\title{
A QUESTÃO DA EQUIDADE NO TOCANTE AO APELO SOCIAL- ECONÔMICO: DECISÃO JUDICIAL E A EQUIDADE
}

\section{ARTIGO ORIGINAL}

CARNEIRO, Dioclécio Salomão ${ }^{1}$

CARNEIRO, Dioclécio Salomão. A questão da equidade no tocante ao apelo social-econômico: Decisão Judicial e a Equidade. Revista Científica Multidisciplinar Núcleo do Conhecimento. Ano 05, Ed. 01, Vol. 05, pp. 41-53. Janeiro de 2020. ISSN: 2448-0959, Link de acesso: https://www.nucleodoconhecimento.com.br/lei/questao-da-equidade

\section{RESUMO}

Em uma sociedade complexa de pensamentos, princípios, crenças morais e religiosas das mais diversas como poderia ser construído e aplicado um modelo de governabilidade que atenda a todos os cidadãos na medida de sua necessidade? É nesse viés que se buscará respostas para vincular a ideia de Justiça de forma a dispor dos recursos sociais, partindo da premissa de que todos são iguais, mas não se retirando toda a desigualdade e sim apenas aquelas que venham a trazer de alguma forma desvantagem a outrem.

Palavras-chave: Equidade, justiça, desigualdade.

\section{INTRODUÇÃO}

Como alternativa a um sistema mais justo e que favoreça o exercício da equidade nos direitos, deveres e oportunidades do bom desenvolvimento das habilidades individuais e do coletivo, tem-se por objeto que as pessoas possam ignorar sua posição na sociedade, suas forças, fraquezas, valores, objetivos e títulos, garantindo assim uma

1 Mestrando em Direito Constitucional - Direitos Fundamentais e Democracia, Bacharel em Direito e Ciências Contábeis. 
espécie de véu da ignorância de forma a garantir que ninguém obtenha vantagens, preferências ou indicações mesmo que involuntariamente, para com isso apropriar-se de uma posição favorável de barganha ou mesmo benefícios seletivos que não atrelem sua conquista através da pura e indelével meritocracia. Isso sem dúvida seria o meio mais adequado e justo dos vários pontos de vista em que indivíduos possam se situar na perspectiva da justiça social, assegurando-Ihes a liberdade de escolha e prosperidade cujo permeia um ambiente de inclusão do qual possam sentir-se em condições de elevar-se e capaz de mudar sua realidade social através do trabalho, estudo e habilidades que venha a adquirir.

\section{A SOCIEDADE E O DESAFIO DA EQUIDADE. AS NECESSIDADES SOCIAIS CADA VEZ MAIS COMPLEXAS NO DESAFIO DA DECISÃO JURÍDICA JUSTA}

A equidade pode estar presente em qualquer momento do ato jurisdicional, não necessariamente atribuindo ou valorando o diferente como algo a ser elevado, mas pelas características de cada indivíduo na medida de sua necessidade o elemento assim necessário e propulsor para a garantia de desfrutar das mesmas oportunidades, livre de vantagens que estão presentes na condição pretérita e sim pelo seu potencial, desenvoltura, capacidade técnica e principalmente disciplina em aguerrear a concretude daquilo que planejado e alcançado com seu mérito próprio, mas na condição de sociedade que o propicie meios viáveis e sustentáveis de elevar o estado social, econômico, cultural e desenvolvimento humano, pois para cada indivíduo que alcance melhor condição, direta e indiretamente beneficia todos que estão a sua volta, seja através do esclarecimento técnico ou pela própria destreza manual em dispor de seu talento. Assim compreende-se nas palavras do autor de que o desenvolvimento sustentável é um processo de aprendizagem social de longo prazo, que por sua vez, é direcionado por políticas públicas orientadas por um plano de desenvolvimento nacional. Assim, a pluralidade de atores sociais e interesses presentes na sociedade colocam-se como um entrave para as políticas públicas para o desenvolvimento sustentável (BEZERRA e BURSZTYN, 2000). Nessa perspectiva o interesse se faz presente e com clareza atinge em beneficio ou em muitos casos nos objetivos 
negativos de governar ou aplicar a interpretação da lei direcionada para interesses pouco republicanos ou em pequena margem se afine ao estudo técnico, mas pelo contrário muito mais atrelado e comprometido ao barganhar em alguma medida benéficos próprios que não os do coletivo ou melhor dizendo nas tão faladas e esperadas políticas de Estado.

Tornar igual do ponto de vista ao acesso a prática e exercício da cidadania é o objeto de aplicação que o estudo se dá, no entanto, essas mesmas diferenças estão intimamente ligadas ao desejo e interpretação do contexto em que o convívio permite sua aparição. Nesses termos temos o direito a ser iguais quando a diferença nos inferioriza; temos o direito a ser diferentes quando a igualdade nos descaracteriza (SANTOS, 2009). As políticas sociais necessitam estar atentas nesse contexto de diferenças, mas sem provocar a exclusão ou tornar obrigatório um modo interpretativo e valorado pela imposição de ações estatais de legislatura e principalmente naqueles locais onde ocorrem vulnerabilidades do público cativo, nas escolas por exemplo.

A formação de uma sociedade inicia-se diretamente nos anos ainda muito tenros da criança e da sociedade, em grande parte de suas ações na fase adulta se dá por aquilo que vivenciaram e das experiências positivas e negativos por qual passaram. É notável de que no pequeno mundo onde as crianças levam sua existência, não há nada que seja percebido e sentido tão precisamente quanto a injustiça (SEN, 2011). Dessa maneira a sociedade deve voltar seus olhos e ações para colaborar seja através do voto, das ações civis públicas, do chamamento ao centro de debates dos problemas e soluções para que se tenha o enfrentamento direto das injustiças que manifestadas pelos indivíduos já desde seu nascimento e desenvolvimento. Não há o que se falar em progresso e desenvolvimento da nação, sem que haja o respeito necessário ao cuidado das necessidades básicas, mas também do desenvolvimento social e cultural de um povo que deseja aniquilar com as aberrações e discrepâncias de participar do mesmo espaço no abismo social.

Ao poder executivo se exige a responsabilidade de arrecadar, conduzir, e aplicar o recurso público da melhor maneira possível, sendo eficiente, transparente, com capacidade de gestão assegurada, fiscalizatório e capacidade de exercer em seu 
ambiente administrativo a investigação, processo e punição necessários para que haja a moralidade sempre presente nas relações públicas entre Estado e cidadão. Assim o poder legislativo exerce o desejo do povo, em suma no modelo representativo que se adota, pois, a vontade geral deve ser atendida, mas também vontade das minorias não pode ser objeto de descaso e tampouco desrespeitada, haja visto serem propostas legítimas e que merecem o debate. No entanto quanto ao Judiciário, sobre ele ainda pesa grande desconfiança, principalmente na Europa, reminiscência de uma época em que este agia como simples longa manus dos reis e demais nobres. Por isso no que toca à interpretação os liberais desenvolveram um sistema que, mais do que antes, mantinha o juiz absolutamente preso à lei (BAHIA, 2004). Para o judiciário o desafio é muito maior assim como sua responsabilidade para com a moralidade e lisura pública na aplicação da lei a todos e todas como cometerem desvios, mas principalmente a aplicação da justiça não só entre relações particulares e sim nas relações públicas que manejam todo o envolvimento da sociedade na gana de permear um governo e Estado saudável, depurado, limpo e transparente das mazelas de momento e oportunas. É nesse contexto que o desafio de não se ter o longa manus judiciário do rei, cujo estará apenas atuando no processo dedicado ao eleitoreiro privilegiado e na clareza de aproximar-se do que de fato ocorre nas injustiças praticadas por uma sociedade que se desenvolveu acreditando em mazelas como 0 meio de sobreviver no convívio desigual.

Cabe a qualquer etapa do passado, presente e futuro a indignação e o ambiente de debate, podendo-se instaurar pesadas críticas ao sistema como um todo, no entanto a propositura de boas soluções, não apenas transferindo ou repassando a terceiro a responsabilidade que é de um ou outro ente público. Cabe nessa crítica, enquanto processo histórico identificado ao utópico, ao radical e ao desmistificador, assume a função de abrir alternativas de ação e margem de possibilidades que se projetam sobre as continuidades históricas (WOLKMER, 2017). Assim no debate que confronta ideias, posições e argumentos as melhores e viáveis proposta se apresentam ao plano real de vida de seus componentes, articulando possíveis mudanças em benefício do maior número possível de pessoas que fazem parte daquela nação abrangida pelo recurso público a ela arrecadado e lhe devolvido sob a forma de serviços prestados. 
Se discute com frequência a existência de direitos humanos aplicáveis que de fato cheguem e sejam percebidos no final da "fila" ou na base da pirâmide social, esse é o maior problema percebido, como fazer as pessoas que mais necessitem do braço estatal perceberem sua presença mas que esse auxílio seja capaz de equilibrar a desigualdade cuja levará anos ou décadas para serem minimizadas. Desta forma, nas palavras de Bodnar (2011), o desenvolvimento é um direito humano inalienável, do qual toda pessoa e todo povo estão hábeis a participar seja do desenvolvimento econômico, social, cultural e político, contribuindo e desfrutando desses direitos e garantias fundamentais de liberdade em sua concretude máxima.

Com esse fundamento pode-se atribuir a necessidade de que todos têm a responsabilidade de arcar com seus deveres, obrigações impostas pelo Estado, porém não se percebe com a mesma eficácia a responsabilidade de em sustentar os cofres públicos, sem o devido retorno satisfatório e que venha a produzir condições de equiparação nas relações sociais entre seus indivíduos uns com os outros. Destaca-se a baixa capacidade de minimizar o impacto na cobrança de impostos frente ao consumo de produtos tidos como básicos entre as mais e menos favorecidas populações, esse apenas um exemplo dentre vários que poderia relacionar.

\section{A JUSTIÇA E A DESIGUALDADE: CAPACIDADE JURÍDICA DE EQUALIZAR SEM PROVOCAR DESVANTAGEM ENTRE AS PARTES}

De forma latente o conceito de justiça vem à tona por diversas meios de interesse dos mais diversos grupos que enxergam nessa palavra múltiplas formas de realizar e colocar em prática políticas sociais de afirmação, planos de governo, atuação da sociedade civil organizada da qual não pode em hipótese alguma deixar de atentar para as boas atitudes, haja visto a demonstração clara da capacidade estatal de não conseguir atender de forma suficiente e necessária aos anseios da população, no entanto não se pode admitir o descomprometimento dos entes públicos e se subverter para com a transferência de responsabilidade para a sociedade civil. Ermínia (2003), declara que as entidades devem laborar mais como auxiliares do corpo principal de 
atuação. Há que se retratar a exclusão social como não sendo passível de mensuração, no entanto os indicadores como a informalidade, a irregularidade, a ilegalidade, pobreza, baixa escolaridade, a ausência da cidadania e a ociosidade como elementos capazes de demonstrar tal feito.

Desta forma é unânime a ligação direta de desigualdades e injustiças pois nesse universo de situações o poder legislativo, executivo e judiciário possuem o nível de responsabilidade para com o bom andamento e correção desses desvios e distorções extremamente prejudiciais para o bom andamento e salutar convívio social.

Para que se tenha atendida as demandas do povo, se faz necessário sua mensuração permanente do que está gerando resultados positivos nos programas desenvolvidos e aferidos, mas também o retorno frente ao custo e benefício produzido, não se pode admitir que na esfera pública pratique-se ações como se o recurso fosse infinito e não houvesse dono, todos são responsáveis, os cidadãos são o Estado, para isso delegase a administração pública a um grupo de pessoas que sejam capazes de administrar, gerir e fazer o máximo possível com o dinheiro empregado. Nessa condição e dentro dessa perspectiva, o Estado de Direito é um conceito formal de acordo com o qual os sistemas jurídicos podem ser mensurados, não a partir de um ponto de vista substantivo, como a justiça ou a liberdade, mas por sua funcionalidade (VIEIRA, 2007). As evidências necessitam serem demonstradas para que projetos eficazes consigam reduzir as desigualdades e pratiquem assim de fato a justiça, onde enganase o pensamento de que uma ou outra esfera está livre da cobrança e sujeito protagonista no desenvolvimento de melhorias para com a efetivação de uma população mais equânime no sentido de garantir o pleno desenvolvimento humano.

A capacidade de controle das demandas sociais, necessárias e urgentes necessitam projetar-se para o presente e com olhar para projetos futuros, o que se esperará para daqui dez, vinte ou até trintas anos na condição de nação desenvolvida que atende sua população da melhor forma possível, seja nas ações básicas de saúde, educação, segurança pública e trabalho, mas também ao completo desenvolvimento do ser humano em suas habilidades e capacidades de ordenar o eixo de sustentabilidade em qualquer sistema, programa ou etapa de aplicação do planejamento. Para Oxhorn e 
Slakmon (2005), a mobilização de cima para baixo, visa a canalização e moderação das demandas das classes mais baixas no sentido de que novas desigualdades são produzidas entre os setores populares cujos "direitos" produzem todos os efeitos, exceto universais.

$\mathrm{Na}$ medida em que novas demandas são atribuídas no dia-a-dia da sociedade moderna, a crescente valorização dos desafios individuais, a velocidade de informação aliada ao despertar de um novo pensamento voltado para o bem-estar, as desigualdades ficam muito a mostras para os olhares daqueles que vivenciam as dificuldades por elas provocadas. No entanto a lentidão pela resposta do ente estatal vai muito aquém da necessidade urgente, o que faz deliberar tamanha restrição, isolamento e subdesenvolvimento de áreas e populações que se quer terão o direito de usufruir das riquezas naturais e produzidas pela nação. Esse seria o maior e mais grave dos problemas, sendo os impedimentos de que todos possam usufruir, ou numa condição realista favorecer ou dar condições necessárias que os indivíduos alcancem seus objetivos tendo como moeda de troca o mérito pessoal e não uma condição social, geográfica ou econômica satisfatória que destoam dos demais e consequentemente gera-se o demasiado ciclo vicioso do qual se torna difícil sua saída.

Para que se seja possível a expressão da vontade singular, os agrupamentos e corporações se fazem necessários a fim de elevar os interesses a um patamar de maior representatividade. Contudo é possível observar essas uniões serem muito mais ativas e acrescidas de interesses que pouco interessam ao coletivo, mas muito mais atendendo ao interesse de uma pequeníssima parcela dentro da esfera pública, o que torna-se prejudicial e agrava ainda mais desequilíbrio na balança social do qual todos tem o dever de trabalhar, produzir, arcar com suas responsabilidades, e também ter o direito ao gozo dos benefícios de uma nação equilibrada e que retorna através da máquina pública as vantagens de forma equitativa na medida da necessidade, mas com uma visão de desenvolvimento e progresso e não apenas assistência perpétua. Desta forma, Assis (2005), relata que a sociedade moderna de cunho liberal, tem "sede" pela liberdade e igualdade, com isso o princípio da subjetividade, 
no tocante a ideia de vontade livre e igual, passa então a ser uma categoria decisiva na arquitetura do direito.

Para que se transforme o mundo das ideias em práticas viáveis de condução, ao plano das leis que conduzem a máquina estatal é de fundamental importância que os representantes estejam em condições de livre pensamento, opiniões e critica para que se possa produzir o melhor que o direito gerido e construído na casa de leis atenda de forma a plena os anseios, apesar de que como sabe-se o recurso é limitado e as demandas pelo que se verifica são infinitas. Sendo então necessário o trabalho bem feito e eficientemente gerido para com as prioridades que venham a fazer sofrer seus indivíduos dentro de um espaço territorial. O desperdício em tempos de crise ou de bonança é imperdoável quando se fala em dinheiro público, fruto do esforço individual de cada contribuinte que separa uma fatia densa de suas riquezas para alimentar o Estado e nesse ponto cabe ressaltar que seus servidores a serviço desse povo não têm gerido com tamanha destreza e precaução o recurso colocados em suas mãos.

Com o passar do tempo a evolução da sociedade tem por parâmetro tomar conhecimento e se popularizar o conhecimento das leis e seus direitos, com isso a busca pelo exercício pleno das garantias constitucionais vão se aglutinando de tal maneira que o mundo distante das leis começa a tornar-se realidade na vida do indivíduo. Desta forma a expansão dos direitos individuais transforma o conceito de cidadania. Antes calcado na liberdade do indivíduo, esta passa a ser dependente da prestação de serviços e de garantias por parte do poder público. Para ser cidadão, é preciso ter acesso a políticas públicas (OLIVEIRA, 2018). O grande desafio seria atuar nessas condições de acesso ao poder público, e com isso colocar em vias de prática o Estado Democrático de Direito sem que essa dependência se torne algo muito voltado ao assistencialismo do que a criação de mecanismos suficientes e necessários para que todos tenham a possibilidade de desenvolver-se e fazer parte na medida de sua participação junto as riquezas produzidas. É inimaginável buscar e propiciar a independência do indivíduo sem que o estado propicie o espaço social justo e principalmente em condições de enfrentar as injustiças que pelo próprio sistema liberal e capitalista venham a ocorrer, sendo, portanto, nesse quesito o olhar 
atento para que seja possível equalizar se não for possível tornar a igualdade de oportunidades. Só assim terá a condição de prover a independência a menor tutela estatal, atribuindo o gasto público a aqueles que de fato necessitam.

\section{CONSEQUÊNCIAS SOCIAIS-ECONÔMICAS NA DEMANDA JURÍDICA: O APELO DA DECISÃO JUSTA}

As demandas jurídicas entre particulares em grande medida são resolvidas no próprio escopo das conciliações e mesmo entre as partes é possível compor soluções pacíficas que se tenha o equilíbrio e satisfação. Entretanto, Farias (2013), revela a recorrente ineficiência governamental, cujo utiliza da repartição de poderes como defeso escudo de sua desacelerada ação, de modo que as lideranças, considerando cada Poder da República, como agentes pessoais, dos quais colocam os interesses dos cidadãos num jogo de oscilações atribuindo de um para o outro a responsabilidade ativa da concretude dos efeitos cidadãos.

Portanto é nessa linha que um poder se exime frente as dificuldades vivenciadas pela população, sendo o paradeiro das reinvindicações associadas ao Poder Judiciário no intento de lançar mão de soluções que deixaram de ser providas no ambiente executivo ou legislativo, abarcando dessa forma o represamento de ações, e pior é que nessa análise judiciária não se faz o condão da capacidade econômica do Estado, mas apenas profere-se o direito da parte interessada. Assim por falta de gestão pública eficaz limita-se de fato que alcance a ponta das necessidades sociais, pelo caminho adequado, a decisão jurídica de que não é seu metiê a administração do recurso público.

A viabilidade de transformar o dinheiro público arrecado em condições necessárias de desenvolvimento e atenção para as necessidades de sua população faz com que o Estado como um todo, na figura dos três poderes o dever ser de funcionar direcionado para as boas políticas de Estado e das de governo, ao caminhar e decidir sob o prisma de tornar sustentável cada ação por ele tomada. Sob pena de tornar-se incapaz de gerir e em consequência perder sua importância como elemento regulador das necessidades humanas. É importante destacar que todo o processo deve estar 
direcionando ao humano e não elencar um valor imaginário como se não houvesse a expectativa de pessoas por detrás de todo e qualquer processo decisório. Desta maneira a Reserva do Possível consiste na realização dos direitos sociais condicionada à quantidade de recursos disponíveis, sob pena de, ao dar enfoque a apenas um desses direitos, inviabilizar a prestação de outros (SOUZA, 2013). Voltase, portanto, ao elemento principal de toda a discussão gerada em torno do poder decisório frente a capacidade pública em oferecer o necessário e suficiente, ainda mais se tratando de um país como o Brasil de veras desigual em todos os aspectos e indicadores sociais. Esses indicadores divulgados nas mídias e em sites oficiais, seja na área da saúde, educação, moradia, cultura, consumo, tecnologia, lazer, segurança e trabalho é possível identificar a falta de coerência nas riquezas produzidas e sua população em maioria se quer tem acesso ao que explorado de seu próprio trabalho. No entanto o problema é histórico e acompanha de longa data tentativas de amenizar tais problemas, cujo Estado tem-se demostrado incapacidade em solucionar problemas mesmo que básicos, e se essa solução vier de forma imediata e obrigatória, como uma decisão judicial por exemplo, corre-se o risco de não analisar todo o contexto, mas sim apenas um item específico e particular dentre várias necessidades sociais.

O bom senso poderia ser aplicado em todas as esferas governamentais, seja no processo legislativo do qual propõe o trilho do qual o poder executivo passaria se utilizando então do processo legal como forma de aplicar aquilo que trata da vontade do povo. Porém os interesses individuais ou corporativos acabam por vezes extrapolando o bom senso do que é público e se deixa de ser pensado no coletivo, criando assim ingerências sobre situações de pouco ou nenhum retorno para o maior número de indivíduos. O processo de positivação dos interesses concorrentes e até conflitantes dos novos atores sociais teve como consequência o colapso da ideia da legalidade, caracterizada pela sua sistematicidade, coerência e unidade (PINTO, 2018). Os interesses particulares quando positivados de forma a atender apenas uma pequena parcela da população causa grave distorção no ciclo de desigualdades produzidas, pois o esforço da máquina pública não estará trabalhando e gastando o precioso recurso público para atender o maior número de indivíduos mas sim uma 
pequena parcela que assim produz ainda mais o destoo da desigualdade e é nessa parcela de atuação de interesse o mais danoso e viciado ciclo de desigualdades, pobreza, baixo desempenho, ausência de melhorias que possam ser sentidas na base da força motriz desse país.

Da forma como se desenvolvem as ações sejam elas de cada ente público e do poder decisório junto as demandas judiciais fixam-se em condições de agir de forma a implementar correções necessárias e neutralizar desigualdades históricas das quais desdobram-se em várias outras consequências sentidas pelos indivíduos. Nesse aspecto dentro da perspectiva da legislação pode-se dizer que somos responsáveis diante dos outros, enquanto somos vida vivendo em comum com outras vidas. Somos responsáveis diante da vida, dos seres, das coisas, do mundo, da natureza (DE FARIAS, 2012). Não há como retirar elementos de ação do ente público que se desdobrem em inúmeras consequências, sejam elas a nível local, estadual ou federal. Por isso o sentido de agir para contra a desigualdade, através de mecanismos que tornem os indivíduos em condições de concorrência equivalente é o desafio não só das políticas públicas e também das decisões jurídicas cujas podem e devem atribuir em seu grau máximo a justiça feita sem que extrapole seus limites, mas que de fato o senso do que é justo seja percebido na sociedade.

Como forma adequada e conquistada pela sociedade é de manter o dever dos órgãos jurídicos responsáveis pelas decisões a independência dos vereditos, fundamentado na legislação em vigor e atrelado aos anseios sociais da justiça como um dos elementos necessários para o combate às desigualdades presentes em cada fato da vida individual e coletiva. Silvestre (2012), observa que órgãos jurisdicionais do Estado possuem o dever jurídico de fundamentação para com seus pronunciamentos, deixando de lado qualquer arbítrio ou interferências estranhas ao sistema legal, seja no que tange a ideologias, arbitrariedades e subjetividades, permitindo assim que as próprias partes façam o controle jurisdicional.

Portando se faz necessário e urgente o acompanhamento muito próximo de cada ato público gerado, em qualquer dos poderes estatais como forma de acompanhar, fiscalizar e atribuir as melhores decisões e exercício da governança que pratique a 
inclusão de todos num sistema de justiça, equidade e que todos possam usufruir de forma a meritocracia ser elevada a um estado de real retribuição, livre de condições pretéritas vantajosas mas sim que a equalização tenha seu papel de dar oportunidades a todos sem provocar distinções que venham a provocar desigualdades pejorativas, exposições desnecessárias ou desagradáveis ao indivíduo.

\section{CONCLUSÃO}

A ideia de praticar o que é justo em muitos casos naturalmente possuem o condão da resposta cuja pessoa é provocada para dar-Ihes sua opinião ou desfecho do problema a ser solucionado, por isso não parece ser absolutamente necessário o conhecimento adquirido, mas já está intrínseco ao Ser o que é justo para com o outro. Como ressalta Rawls (1997), nossa dependência da intuição pode ser minorada pela colocação de questões mais definidas e pela substituição de juízos morais por juízos da sabedoria. Nesse viés a sabedoria ultrapassa conceitos morais ou valores temporais, fazendo com que o justo se sobreponha as mais diversas situações propostas e tendo esse a capacidade de escolher de forma natural o justo. Não se espera de forma consciente outra opção senão aquela que venha a combater injustiças e eleve o bemestar ao grau de finalidade proposta pelo conhecimento humano, disposto no centro das decisões importantes que movimentam e impulsionam o desenvolvimento da paz justa e imune de poderes alheios ao que naturalmente se consolida em um ambiente de igualdade a todos os seus pares.

\section{REFERÊNCIAS}

ASSIS, Olney Queiroz. Princípio da autonomia da vontade x princípio da boa-fé (objetiva): uma investigação filosófica com repercussão na teoria dos contratos. Jus Navigandi, 2005.

BAHIA, Alexandre. A Interpretação Jurídica no Estado Democrático de Direito: contribuição a partir da Teoria do Discurso de J. Habermas. Jurisdição e hermenêutica constitucional. Belo Horizonte: Mandamentos, p. 301-357, 2004. 
BARBOSA, Gisele Silva. O desafio do desenvolvimento sustentável. Revista Visões, v. 4, n. 1, p. 1-11, 2008.

BODNAR, Zenildo. A sustentabilidade por meio do direito e da jurisdição. Revista Jurídica Cesumar-Mestrado, v. 11, n. 1, 2011.

DE FARIAS, André Brayner. Por que a responsabilidade?-Why responsibility?. CONJECTURA: filosofia e educação, v. 17, n. 1, 2012.

ERMÍNIA, Maricato. Metrópole, legislação e desigualdade. Estudos avançados, v. 17, n. 48, p. 151-166, 2003.

FARIAS, Clovis Renato Costa. A fragilização dos direitos fundamentais de segunda dimensão pelo poder judiciário e suas consequências sócio-jurídicas. Acesso em, v. 4, 2013.

JUSTIÇA [recurso eletrônico] / Michael J. Sandel; Tradução de Heloisa Matias e Maria Alice Máximo. - Rio de Janeiro: Civilização Brasileira, 2015.

OLIVEIRA, Clarice G. Crise, Progresso, Revolução E Involução No Direito. Revista Da Agu, v. 17, n. 4, 2018.

OXHORN, Philip; SLAKMON, Catherine. Micro-justiça, desigualdade e cidadania democrática. A construção da sociedade civil através da Justiça Restaurativa no Brasil. Justiça Restaurativa. Coletânea de artigos, p. 189-212, 2005.

PINTO, Oriana Piske de Azevedo Magalhães. Nova Postura Político-Social Do Poder Judiciário. 2008.

RAWLS, John. Uma teoria da justiça / John Rawl ; Tradução Almiro Pisetta e Lenita M. R. Esteves - São Paulo: Martins Fontes, 1997 - (Ensino Superior).

SANTOS, Boaventura de Sousa. Direitos Humanos: o desafio da interculturalidade. Revista direitos humanos, n. 2, p. 10-18, 2009. 
SEN, Amartya. A ideia de justiça. Editora Companhia das Letras, 2011.

SILVESTRE, Ana Carolina Faria. As Emoções Racionais E A Realização Prática Do Direito À Luz Da Proposta De Martha Nussbaum-; O Papel Das Obras Literárias E Das Emoções Racionais No Processo De Tomada De Decisão Judicial. Revista de Estudos Jurídicos UNESP, v. 15, n. 22, 2012.

SOUZA, Lucas Daniel Ferreira de. Reserva do possível e o mínimo existencial: embate entre direitos fundamentais e limitações orçamentárias. Âmbito Jurídico, Rio Grande, XVI, n. 116, 2013.

VIEIRA, Oscar Vilhena. A desigualdade e a subversão do Estado de Direito. Revista Internacional de Direitos Humanos, v. 4, n. 6, p. 28-51, 2007.

WOLKMER, Antonio Carlos. Introdução ao pensamento jurídico crítico. Editora Saraiva, 2017.

Enviado: Setembro, 2019.

Aprovado: Janeiro, 2020. 